\title{
Subjective health and quality of life among elderly people living with chronic multimorbidity and difficulty in activities of daily living in rural South Africa
}

This article was published in the following Dove Press journal:

Clinical Interventions in Aging

Chao Wang, ${ }^{1,2}$ Run Pu, ${ }^{3}$ Zhifei Li, ${ }^{3}$ Lu Ji, ${ }^{4,5}$ Xiaosong Li, ${ }^{6}$

Bishwajit Ghose, ${ }^{7}$ Rui Huang, ${ }^{8}$

Shangfeng Tang ${ }^{4,5}$

'School of Public Policy and Management, China University of Mining and Technology, Xuzhou, People's Republic of China; ${ }^{2}$ School of Safety Engineering, China University of Mining and Technology, Xuzhou, People's Republic of China; ${ }^{3}$ Department of Industrial

Development, China National Center for Biotechnology Development, Beijing, People's Republic of China; ${ }^{4}$ School of Medicine and Health Management, Tongii Medical College, Huazhong University of Science and Technology, Wuhan, People's Republic of China; ${ }^{5}$ Research Center for Rural Health Service, Key Research Institute of Humanities and Social Sciences of Hubei Provincial Department of Education, Wuhan, People's Republic of China; ${ }^{6}$ Clinical Molecular Medicine Testing Center, The First Affiliated Hospital of Chongqing Medical University, Chongqing, People's Republic of China; ${ }^{7}$ Faculty of Social Sciences, School of International Development and Global Studies, University of Ottawa, Ottawa, ON, Canada; ${ }^{8}$ School of Pharmacy, Tongji Medical College, Huazhong University of Science and Technology, Wuhan, People's Republic of China

Correspondence: Rui Huang School of Pharmacy, Tongji Medical College, Huazhong University of Science and Technology, I 3 Hangkong Road, Wuhan 430030, Hubei, People's Republic of China Email hys19810612@163.com

Shangfeng Tang

School of Medicine and Health Management, Tongji Medical College, Huazhong University of Science and Technology, I 3 Hangkong

Road, Wuhan 430030, Hubei, People's

Republic of China

Email sftang2018@hust.edu.cn
Background: South Africa has been experiencing a growing proportion of elderly population with rapid increases in the burden of non-communicable diseases (NCDs) characteristic of population aging. Rural areas in South Africa represent a far smaller fraction of the population, however, share a relatively higher burden of NCDs. In the current literature, there is limited evidence on rural studies in the context of chronic diseases and activities of daily living (ADLs) among the elderly population (60 years and above) in South Africa.

Purpose: In this regard, we undertook the present study with the objective of examining the demographic, behavioral, and socioeconomic predictors of subjective health, depression, and quality of life among elderly men and women living in the rural areas $(n=2,627)$.

Methods: Data for this study were collected from the Health and Aging in Africa: A Longitudinal Study of an INDEPTH Community in South Africa (HAALSI). Main explanatory variables were selfreported NCDs and difficulties in ADLs. The predictors of subjective health, depression, and quality of life were assessed using multivariable regression methods.

Results: We found that the proportion of participants who reported good health, not having depression, and good quality of life was respectively $44.7 \%, 81.3 \%$, and $63 \%$. Women in the oldest age group ( $80+$ years) were significantly less likely to report good health $(\mathrm{OR}=0.577,95 \% \mathrm{CI}=0.420$, $0.793)$ and quality of life ( $\mathrm{OR}=0.709,95 \% \mathrm{CI}=0.539,0.933)$ compared with those in the youngest group. Having more than one chronic condition and ADL difficulties significantly lowered the odds of good health, having no depression, and quality of life among men and women.

Conclusion: The present findings suggest the involvement of sociodemographic factors in health and quality of life outcomes among elderly South Africans, and call for enhanced efforts to address these health limiting conditions such as ADLs and chronic multimorbidity. Keywords: activities of daily, elderly population, non-communicable diseases, rural health, South Africa

\section{Introduction}

Globally, there is growing research and policy attention regarding the changing demography marked especially by increasing life expectancy (LE), population aging, and ensuing public health and health care challenges in limited-resource settings. The African region has the youngest population worldwide and has been experiencing a rapid rise in LE during last 10-15 years. ${ }^{1}$ Between 2000-2016, the average LE in the WHO African Region increased by 10.3 years compared with 
global average of 5.5 years. ${ }^{2}$ Increasing LE, as an indicator of health, material and overall human development, is also triggering population aging with ensuing epidemiological transition marked by a rising proportion of population living with chronic diseases. ${ }^{3-5}$ This transition is taking place at a faster pace in relatively wealthier countries like South Africa which translates to mounting pressure on a health care system that is designed mainly to treat acute infectious diseases and single morbidities. ${ }^{6-10}$ Whereas, elderly individuals tend to experience multiple chronic conditions (known as chronic multimorbidity), a phenomenon that is particularly challenging for caregiving services and requires more sophisticated management strategies and a higher level of care. The situation gets particularly challenging in the presence of functional disabilities or disabilities in activities of daily living (ADLs) such as eating, self-care, and movement.

South Africa represents one of the most rapidly aging countries in the sub-Saharan African region (4.6 million in 2017 vs 2.8 million in 1996), ${ }^{11}$ has the highest prevalence of obesity, and consequently, a high burden of non-communicable diseases (NCDs). The population is predominantly urbanized (urban population constituting about 2/3 of the total population) with significant urban-rural disparities in disease burden, health care seeking, and the allocation of care resources. ${ }^{12-15}$ Although the rural population also shares a high burden of NCDs, ${ }^{16}$ there is a dearth of rural studies in the context of subjective health, and quality of life (QoL) among the elderly population living with NCDs in South Africa.

The concepts of subjective measures of health such as self-reported health (SRH) and QoL are becoming increasingly popular in the context of social determinants of health. There are several models of health determinants such as biopsychosocial model which maintains that health and QoL outcomes are influenced by a range of demographic, socioeconomic, environmental, biological, nutritional, social, and behavioral factors. ${ }^{17}$ Unlike clinical diagnosis, the subjective constructs of health give an overall sociocultural condition of individual health which has been found to be a strong predictor of general health condition and mortality. In high-income countries, both SRH and QoL have been growing in popularity, especially among public health researchers in high-income countries. However, there is limited research evidence on these topics in South Africa, especially in the rural context. In this regard, we undertook the present study using data from the Health and Aging in Africa: A Longitudinal Study of an INDEPTH Community in South Africa
(HAALSI). The objective was to examine the demographic, behavioral, and socioeconomic predictors of subjective health, depression, and QoL among the elderly population living with chronic multimorbidity and ADL difficulties. The findings are expected to be of special importance to health care researchers and policy makers in the areas of rural health in South Africa and countries in similar stages of demographic and economic transition.

\section{Methods \\ Data source}

Data for this study were collected from The Health and Aging Study in Africa: A Longitudinal Study of an INDEPTH Community in South Africa (HAALSI). The study was led by an interdisciplinary team of collaborators from Harvard T.H. Chan School of Public Health, University of Witwatersrand in South Africa and The INDEPTH Network. ${ }^{18}$ This is the first survey to provide health and demographic data on the rural population in South Africa on a range of indicators relevant to elderly health including health behavior (such as tobacco and alcohol use, physical activity), physical and psychosocial health and well-being health, functional disabilities, and chronic diseases. Recruitment of participants took place from November 2014 to November 2015, they were selected randomly from the Agincourt Health and Demographic Surveillance Site (HDSS). ${ }^{19}$ The survey was administered by local fieldworkers using Computer-Assisted Personal Interview system. The 2015 survey was the baseline wave of data collection for HAALSI that included 5,890 men and women aged 40 and older. For the present study, we considered only the elderly population (aged 60 years and older) who provided information on the variables included in the analysis. Detailed descriptions of the data collection procedures have been published elsewhere. ${ }^{18,20}$

\section{Measures}

\section{Dependent variables}

The dependent variables included in this study were selfreported: 1) health, 2) depression, and 3) QoL. These were assessed based on the following three questions respectively:

1. "In general, how would you rate your health today", with the answers ranging from (1) very good, (2) good, (3) moderate, (4) bad (5) very bad. This was finally categorized as "Good" (by merging responses from 1-2) and "Not good" (by merging responses from $3-5) .^{21}$ 
2. "Would you say yes or no? Much of the time in the past week, you felt depressed", and "Much of the time in the past week, you felt sad". The answers were coded as "Depressed" if they responded yes to these questions, and "Not depressed" if they responded otherwise.

3. "All things considered, how satisfied are you with your life as a whole these days? Use a 0 to 10 scale, where 0 is dissatisfied and 10 is satisfied". For this study, the answers were coded as "Good" (above 5) and "Not good" (below average score, 5 and less).

Regarding health status, personal rating of general health during the survey or the recent time is more commonly used in the public health literature: ${ }^{22,23}$

- In general, how would you rate your health, today?

- In general, how would you rate your physical health?

For depression, one-item questions are used both among the healthy population and those living with physical conditions: ${ }^{24,25}$

- In the past 2 weeks, have you felt depressed?

- In the past 30 days, for about how many days have you felt sad, blue?

Similar approaches have been used for assessing subjective QoL as well: ${ }^{26}$

- All things considered, how satisfied are you with your life as a whole these days?

- In general, how satisfied are you with your life?

- Overall, how satisfied are you with your life nowadays?

Empirical studies have shown that these single-item life satisfaction questions perform very similar compared with the Satisfaction with Life Scale as they produce virtually identical answers to substantive questions regardless of the measure used. ${ }^{26}$

Selection of the covariates was done in light of the biopsychosocial theory of determinants of health which maintains that health is an outcome of the interaction of biological, dietary, social, environmental, and psychological factors. ${ }^{27,28}$ From this viewpoint, main explanatory variables were self-reported presence of chronic diseases and ADL difficulties. Chronic conditions included: angina, diabetes, stroke, high blood pressure, cataract, and stroke. This was categorized as: none, 1 condition, $>1$ conditions (multimorbidity). ${ }^{29} \mathrm{ADL}$ was defined as presence of bathing, getting in and out of bed, dressing, eating, using toilet, and walking across rooms, and was categorized as "has ADL disabilities" and "no ADL disabilities".

Basic demographic, behavioral, and socioeconomic characteristics were added as explanatory variables. The selection procedure of these variables was guided by a thorough literature review of the outcome variables in PubMed as well as availability of these variables on the dataset. The review suggested the involvement of factors across several domains of physical and mental health and QoL: demographic (eg, age, sex), financial (eg, wealth status, employment), behavioral (eg, smoking, drinking), relational (eg, living arrangement/marital status), and other physical conditions (eg, sleep, NCDs). ${ }^{30}$ The following were finally included in the analysis: age (60-69, 70-79, 80+); sex (male, female); current marital status (unmarried, married); education (no formal education, some primary/1-7 years, some secondary/8-11 years, secondary or more/12+ years); employed (yes, no); wealth status (poor, not poor); living environment (not satisfactory, satisfactory); ever smoker (no, yes); ever drinks alcohol (no, yes); takes exercise during leisure (no, yes); self-reported sleep quality (not good, good).

Living environment was assessed based on the question on whether or not the respondent lives in the village "In general, how much do you like your village? Do you like it a lot, like it, dislike it, dislike it a lot, or don't care?" Their answers were categorized as "satisfactory" if they responded "like it" and "like a lot" and not satisfactory if they responded "dislike it" and "dislike a lot". Wealth index (Wealth Quintile) was calculated using the method applied in the Demographic and Health Surveys ${ }^{31}$ which provides a composite indicator of household wealth condition. The index is constructed by principal components analysis of scores assigned on individual household possessions eg, consumer goods, dwelling characteristics. Households are then ranked based on individual scores to range between poorest, poorer, middle, richer, and richest. ${ }^{32}$

\section{Data analysis}

Data analyses were performed using Stata 14. Datasets were first checked for missing values and outliers. Basic demographic, behavioral, and socioeconomic characteristics were presented using descriptive statistics. Chi-squared bivariate tests were used to assess the statistical significance between the three outcomes (SRH, depression, and QoL) 
with the predictor variables. Variables that showed association at 0.25 at bivariate level were retained for multivariable analysis. $^{33}$ At the next step, the association between the three outcome and explanatory variables was calculated by multivariable regression methods. Given the dichotomous nature of the outcome variables, binary logistic regression model was used to generate the ORs and their $95 \%$ CIs. Model statistics were assessed by pseudo- $R^{2}$ values. All statistical tests were two-tailed and $p$-values below 0.05 were considered statistically significant

\section{Ethical approval}

All participants gave informed consent prior to taking part in the interviews. Data were open-access and available online in anonymized form; therefore, no additional approval was necessary.

\section{Results}

\section{Sample description}

Basic sociodemographic characteristics of the sample population were presented in Table 1 . The proportion of participants who reported good health, not having depression, and good QoL was respectively 44.7\%, 81.3\%, and $63 \%$. The table also indicates that the proportion of good $\mathrm{SRH}$ was relatively higher among those in the youngest age group of 60-69 years, female, currently unmarried, no employment, satisfied with living environment, never smoked tobacco, no chronic conditions and ADL difficulties. With some exceptions, similar sociodemographic associations were observed for depression and QoL as well.

\section{Results of regression analyses}

The predictors of good SRH, depression, and QoL were presented in Tables 2-4 respectively. The results revealed certain sex disparities in the associations. Compared with those in the youngest age group, women in the highest age group were significantly less likely to report good health $(\mathrm{OR}=0.577,95 \% \mathrm{CI}=0.420,0.793)$ (Table 2) and $\mathrm{QoL}$ $(\mathrm{OR}=0.709,95 \% \mathrm{CI}=0.539,0.933)$ (Table 4). Marital status did not show any association with any of the outcomes among men or women. Not surprisingly, having educational experience was associated with higher odds of health and QoL among both men and women. Regarding financial indicators, employment status was not associated with the outcomes, however, being in not poor households was associated with high odds of QoL among men $(\mathrm{OR}=1.497$,
$95 \% \mathrm{CI}=1.138,1.969)$. Satisfactory living environment was associated with higher odds of good health only among women $(\mathrm{OR}=3.152,95 \% \mathrm{CI}=1.161,8.553)$. In general, health behaviors including smoking and alcohol drinking did not show any noticeable association with the outcome variables. Drinking alcohol increased the odds of not being depressed (also in sex-specific analysis) and having good satisfaction with life (not significant in sex-specific analysis).

However, alcohol drinking was inversely associated with having depression among both men and women. Finally, having more than one chronic condition and ADL difficulties significantly lowered the odds of good health, having no depression and QoL among men and women.

\section{Discussion}

In the present study we aimed to investigate the predictors of subjective health, depression, and QoL among elderly men and women in rural South Africa. More than $2 / 5$ of the participants reported good health and 2/3 reported good QoL, whereas 1/5 reported having depressive symptoms. As expected, the likelihood of reporting good SRH was relatively higher among those in the youngest age group. With increasing age, there is a higher risk of developing physical and mental morbidities that can affect subjective health conditions. Similar findings were reported by a study on Ghanaian elderly population, ie, subjective health status was worse in the high age groups. ${ }^{34}$ In addition to age, being female, currently unmarried, having no employment, being satisfied with living environment, never smoked tobacco, no chronic conditions and ADL difficulties, were also associated with good SRH and QoL.

Given the growing phenomenon of population aging and burden of NCDs in South Africa, evidence on the sociodemographic patterns of health and well-being are crucial to design health interventions and appropriate social policies to promote health and QoL among the elderly. This is particularly the case for geographically and socioeconomically disadvantaged populations in the country, such as those in the rural areas. From this perspective, the findings of the present study can be useful to health researchers and program planners in the rural settings in South Africa and in countries with similar sociodemographic characteristics. Although this was a cross-sectional analysis, several interesting findings emerged from the current study that are worthy of note. As expected, participants in the highest age groups were least likely to report good health and 
Table I Sociodemographic profile of the sample population. HAALSI $2015(n=2,627)$

\begin{tabular}{|c|c|c|c|c|c|c|c|}
\hline & \multirow[t]{3}{*}{ Sample \% } & \multicolumn{2}{|l|}{ SRH } & \multicolumn{2}{|c|}{ Depression } & \multicolumn{2}{|c|}{ Quality of life } \\
\hline & & Not good & Good & Yes & No & Not good & Good \\
\hline & & 55.3 & 44.7 & 18.7 & 81.3 & 37.0 & 63.0 \\
\hline \multicolumn{8}{|l|}{ Age groups } \\
\hline $60-69$ & 47.7 & 44.7 & 51.5 & 42.9 & 49.9 & 39.4 & 52.6 \\
\hline $70-79$ & 32.1 & 30.9 & 33.7 & 30.4 & 32.5 & 33.3 & 31.5 \\
\hline $80+$ & 20.1 & 24.4 & 14.8 & 26.8 & 17.6 & 27.3 & 15.9 \\
\hline p-value & & \multicolumn{2}{|l|}{0.005} & \multicolumn{2}{|c|}{$<0.001$} & \multicolumn{2}{|l|}{$<0.001$} \\
\hline \multicolumn{8}{|l|}{ Sex } \\
\hline Male & 47.7 & 46.8 & 48.9 & 41.6 & 49.3 & 44.3 & 49.7 \\
\hline Female & 52.3 & 53.2 & 51.1 & 58.4 & 50.7 & 55.7 & 50.3 \\
\hline p-value & & \multicolumn{2}{|l|}{0.150} & \multicolumn{2}{|c|}{$<0.001$} & \multicolumn{2}{|l|}{$<0.001$} \\
\hline \multicolumn{8}{|l|}{ Current marital status } \\
\hline Unmarried & 53.4 & 55.4 & 51.0 & 57.7 & 51.7 & 59.2 & 50.1 \\
\hline Married & 46.5 & 44.6 & 49.0 & 42.3 & 48.3 & 40.8 & 49.9 \\
\hline p-value & & \multicolumn{2}{|l|}{0.013} & \multicolumn{2}{|c|}{$<0.001$} & \multicolumn{2}{|l|}{$<0.001$} \\
\hline \multicolumn{8}{|l|}{ Education } \\
\hline No formal education & 60.5 & 63.1 & 57.8 & 60.8 & 59.9 & 71.3 & 54.5 \\
\hline Some primary ( $\mathrm{I}-7$ years) & 32.5 & 29.9 & 36.0 & 33.3 & 33.1 & 24.7 & 37.3 \\
\hline Some secondary (8-II years) & 4.9 & 5.5 & 4.4 & 4.0 & 5.4 & 3.6 & 5.8 \\
\hline Secondary or more $(12+$ years $)$ & 1.6 & 1.5 & 1.8 & 1.8 & 1.6 & 0.4 & 2.4 \\
\hline$p$-value & & \multicolumn{2}{|l|}{0.005} & \multicolumn{2}{|c|}{0.116} & \multicolumn{2}{|l|}{$<0.001$} \\
\hline \multicolumn{8}{|l|}{ Employed } \\
\hline Yes & 4.2 & 3.6 & 4.9 & 3.8 & 4.4 & 2.8 & 5.0 \\
\hline No & 95.8 & 96.4 & 95.1 & 96.2 & 95.6 & 97.2 & 95.0 \\
\hline p-value & & \multicolumn{2}{|l|}{0.52} & \multicolumn{2}{|c|}{$<0.001$} & \multicolumn{2}{|l|}{$<0.001$} \\
\hline Wealth status & & & & & & & \\
\hline Not poor & 61.0 & 61.5 & 60.3 & 63.4 & 60.1 & 67.6 & 57.1 \\
\hline Poor & 39.0 & 38.5 & 39.7 & 36.6 & 39.9 & 32.4 & 42.9 \\
\hline p-value & & 0.127 & & $<0.00$ & & $<0.001$ & \\
\hline Living environment & & & & & & & \\
\hline Satisfactory & 1.7 & 2.3 & 0.9 & 2.2 & 1.5 & 2.3 & 1.3 \\
\hline Not satisfactory & 95.3 & 97.7 & 99.1 & 97.8 & 98.5 & 97.7 & 98.7 \\
\hline p-value & & $<0.001$ & & $<0.00$ & & $<0.001$ & \\
\hline Ever smoker & & & & & & & \\
\hline Yes & 21.1 & 20.9 & 21.3 & 19.5 & 21.9 & 18.4 & 22.7 \\
\hline No & 78.9 & 79.1 & 78.7 & 80.5 & 78.1 & 81.6 & 77.3 \\
\hline p-value & & $<0.001$ & & $<0.00$ & & $<0.001$ & \\
\hline Ever drinks alcohol & & & & & & & \\
\hline Yes & 50.1 & 49.5 & 50.9 & 55.7 & 49.3 & 52.2 & 48.9 \\
\hline No & 49.9 & 50.5 & 49.1 & 44.3 & 50.7 & 47.8 & 51.1 \\
\hline$p$-value & & 0.147 & & $<0.00$ & & $<0.001$ & \\
\hline
\end{tabular}


Table I (Continued).

\begin{tabular}{|c|c|c|c|c|c|c|c|}
\hline & \multirow[t]{3}{*}{ Sample \% } & \multicolumn{2}{|l|}{ SRH } & \multicolumn{2}{|c|}{ Depression } & \multicolumn{2}{|c|}{ Quality of life } \\
\hline & & Not good & Good & Yes & No & Not good & Good \\
\hline & & 55.3 & 44.7 & 18.7 & 81.3 & 37.0 & 63.0 \\
\hline \multicolumn{8}{|l|}{ Leisure time PA } \\
\hline Yes & 35.0 & 35.7 & 34.0 & 41.2 & 31.6 & 40.7 & 31.6 \\
\hline No & 65.0 & 64.3 & 66.0 & 58.8 & 68.4 & 59.3 & 68.4 \\
\hline$p$-value & & \multicolumn{2}{|l|}{0.101} & \multicolumn{2}{|c|}{$<0.001$} & \multicolumn{2}{|l|}{$<0.001$} \\
\hline \multicolumn{8}{|l|}{ NCDs } \\
\hline None & 42.6 & 39.6 & 46.2 & 34.0 & 44.7 & 40.9 & 43.6 \\
\hline I & 40.7 & 40.6 & 40.9 & 41.6 & 41.0 & 38.0 & 42.3 \\
\hline$>1$ & 16.7 & 19.8 & 12.8 & 24.3 & 14.4 & 21.1 & 14.1 \\
\hline p-value & & \multicolumn{2}{|l|}{$<0.001$} & \multicolumn{2}{|c|}{$<0.001$} & \multicolumn{2}{|l|}{$<0.001$} \\
\hline \multicolumn{8}{|l|}{ ADL difficulties } \\
\hline No & 87.4 & 82.1 & 93.9 & 77.6 & 91.2 & 78.3 & 92.7 \\
\hline Yes & 12.6 & 17.9 & 6.1 & 22.4 & 8.8 & 21.7 & 7.3 \\
\hline$p$-value & & \multicolumn{2}{|l|}{$<0.001$} & \multicolumn{2}{|c|}{$<0.001$} & \multicolumn{2}{|l|}{$<0.001$} \\
\hline
\end{tabular}

Abbreviations: HAALSI, Health and Aging in Africa: A Longitudinal Study of an INDEPTH Community in South Africa; SRH, self-reported health; PA, physical activity; NCDs, non-communicable diseases; ADL, activities of daily living.

QoL, indicating the negative effect of aging on health status and need for greater care.

Unlike some previous research, marital status did not show any association with health or QoL either among men or among women. ${ }^{35,36}$ Married individuals generally show better subjective physical and emotional health because of their greater economic resources and more social support. ${ }^{35}$ In contrast to the present findings, a multi-country study based on World Health Survey showed that marital status was significantly associated with subjective health among both men and women. ${ }^{37}$ Our findings thus indicate that cross-cultural variations do exist in these associations, meaning that the positive role of well-known factors such as education and being married may not apply to all populations. Being female did not show any differential effect on health or QoL, however, it was associated with higher likelihood of depression compared with their male counterparts. The sex disparity in the prevalence of depression was highlighted in previous studies as well, ${ }^{38,39}$ and remains open to further investigation in the African population. Women reported better health more often when living in a satisfactory environment, but the associations were not similar among men, suggesting a sex pattern in the influences of environmental factors on subjective health. This is an interesting finding, however there is no concrete evidence of similar research topics. A possible explanation for this difference could be due to the way men and women attach importance to living environment and perceive its impact on health status. This finding requires thorough investigation to explore the underlying causes behind this sex disparity.

Regarding health behavior, alcohol drinking was inversely associated with having depression among both men and women, which is a potentially worrisome finding and warrants special policy attention. Elderly men and women may resort to alcohol drinking to cope with the health and emotional challenges of their everyday life, and may end up regarding alcohol as a protective mechanism against succumbing to ill health. Previous findings from Ghana also reported a positive association between alcohol drinking and subjective health. ${ }^{34}$ This finding should nonetheless be interpreted with caution as we had no information on the volume of drinking which could make an important difference in the analysis. Some level of drinking is considered healthy and socially acceptable across many cultures. Apart from the sociodemographic factors, the most important findings were the strong negative associations between health, depression, and QoL with chronic multimorbidity and ADL difficulties, and the negative associations were observed for both men and women. Living with 
Table 2 Predictors of good subjective health among elderly South Africans. HAALSI 2015

\begin{tabular}{|c|c|c|c|}
\hline & Overall & Male & Female \\
\hline $\begin{array}{l}\text { Age (60-69) } \\
70-79 \\
80+\end{array}$ & $\begin{array}{l}\text { I } \\
\text { I.033 } \\
{[0.861,1.240]} \\
0.664 * * * \\
{[0.526,0.837]}\end{array}$ & $\begin{array}{l}\text { I } \\
\text { I.256 } \\
{[0.969,1.627]} \\
0.735 \\
{[0.518,1.043]}\end{array}$ & $\begin{array}{l}\mathrm{I} \\
0.843 \\
{[0.649,1.095]} \\
0.577 * * * \\
{[0.420,0.793]}\end{array}$ \\
\hline $\begin{array}{l}\text { Sex (male) } \\
\text { Female }\end{array}$ & $\begin{array}{l}\mathrm{I} \\
\mathrm{I} .032 \\
{[0.834,1.275]}\end{array}$ & NA & NA \\
\hline $\begin{array}{l}\text { Current marital status (unmarried) } \\
\text { Married }\end{array}$ & $\begin{array}{l}\mathrm{I} \\
1.088 \\
{[0.903,1.310]}\end{array}$ & $\begin{array}{l}\mathrm{I} \\
\mathrm{I} .230 \\
{[0.945,1.602]}\end{array}$ & $\begin{array}{l}\mathrm{I} \\
0.930 \\
{[0.711,1.217]}\end{array}$ \\
\hline $\begin{array}{l}\text { Education (no formal education) } \\
\text { Some primary ( } 1-7 \text { years) } \\
\text { Some secondary (8-1I years) } \\
\text { Secondary or more ( } 12+\text { years) }\end{array}$ & $\begin{array}{l}\mathrm{I} \\
\mathrm{I} .239 * \\
{[1.036,1.482]} \\
0.768 \\
{[0.527,1.119]} \\
1.104 \\
{[0.590,2.067]}\end{array}$ & $\begin{array}{l}\text { I } \\
\text { I.40I** } \\
{[1.086,1.808]} \\
0.654 \\
{[0.406,1.051]} \\
1.106 \\
{[0.528,2.316]}\end{array}$ & $\begin{array}{l}\mathrm{I} \\
\mathrm{I} .115 \\
{[0.865,1.439]} \\
\mathrm{I} .115 \\
{[0.586,2.122]} \\
\mathrm{I} .189 \\
{[0.345,4.102]}\end{array}$ \\
\hline $\begin{array}{l}\text { Employed (yes) } \\
\text { No }\end{array}$ & $\begin{array}{l}I \\
0.871 \\
{[0.591,1.283]}\end{array}$ & $\begin{array}{l}\text { I } \\
0.843 \\
{[0.534,1.332]}\end{array}$ & $\begin{array}{l}\mathrm{I} \\
0.834 \\
{[0.390,1.785]}\end{array}$ \\
\hline $\begin{array}{l}\text { Wealth status (poor) } \\
\text { Not poor }\end{array}$ & $\begin{array}{l}\mathrm{I} \\
0.971 \\
{[0.817,1.153]}\end{array}$ & $\begin{array}{l}\mathrm{I} \\
\mathrm{I} .034 \\
{[0.806,1.327]}\end{array}$ & $\begin{array}{l}\mathrm{I} \\
0.934 \\
{[0.734, \mathrm{I} .188]}\end{array}$ \\
\hline $\begin{array}{l}\text { Living environment (not satisfactory) } \\
\text { Satisfactory }\end{array}$ & $\begin{array}{l}1 \\
2.103 * \\
{[1.038,4.263]}\end{array}$ & $\begin{array}{l}\text { I } \\
\text { I. } 274 \\
{[0.443,3.659]}\end{array}$ & $\begin{array}{l}1 \\
3.152 * \\
{[1.161,8.553]}\end{array}$ \\
\hline $\begin{array}{l}\text { Ever smoker (no) } \\
\text { Yes }\end{array}$ & $\begin{array}{l}\mathrm{I} \\
\mathrm{I} .135 \\
{[0.899,1.433]}\end{array}$ & $\begin{array}{l}\text { I } \\
\text { I.077 } \\
{[0.834,1.389]}\end{array}$ & $\begin{array}{l}\text { I } \\
\text { I.228 } \\
{[0.547,2.757]}\end{array}$ \\
\hline $\begin{array}{l}\text { Ever drinks alcohol (no) } \\
\text { Yes }\end{array}$ & $\begin{array}{l}\text { I } \\
0.874 \\
{[0.729,1.049]}\end{array}$ & $\begin{array}{l}\text { I } \\
0.966 \\
{[0.733,1.274]}\end{array}$ & $\begin{array}{l}\text { I } \\
0.796 \\
{[0.622,1.019]}\end{array}$ \\
\hline $\begin{array}{l}\text { Takes exercise (no) } \\
\text { Yes }\end{array}$ & $\begin{array}{l}\text { I } \\
0.901 * \\
{[0.699,0.989]}\end{array}$ & $\begin{array}{l}I \\
0.788 \\
{[0.616,1.009]}\end{array}$ & $\begin{array}{l}\mathrm{I} \\
0.878 \\
{[0.686,1.124]}\end{array}$ \\
\hline $\begin{array}{l}\text { NCDs (none) } \\
\text { I } \\
>1\end{array}$ & $\begin{array}{l}\mathrm{I} \\
0.904 \\
{[0.760,1.076]} \\
0.622 * * * \\
{[0.489,0.792]}\end{array}$ & $\begin{array}{l}I \\
0.921 \\
{[0.715,1.187]} \\
0.58 I^{* *} \\
{[0.408,0.825]}\end{array}$ & $\begin{array}{l}1 \\
0.894 \\
{[0.701,1.140]} \\
0.647^{*} \\
{[0.462,0.906]}\end{array}$ \\
\hline $\begin{array}{l}\text { ADL difficulties (no) } \\
\text { Yes }\end{array}$ & $\begin{array}{l}\text { I } \\
0.372 * * * \\
{[0.277,0.500]}\end{array}$ & $\begin{array}{l}\text { I } \\
0.475 * * * \\
{[0.311,0.723]}\end{array}$ & $\begin{array}{l}\mathrm{I} \\
0.300 * * * \\
{[0.197,0.459]}\end{array}$ \\
\hline
\end{tabular}

(Continued) 
Table 2 (Continued).

\begin{tabular}{|l|l|l|l|}
\hline & Overall & Male & Female \\
\hline $\mathrm{N}$ & 2627 & 1259 & 1368 \\
\hline Adjusted $R^{2}$ & 0.431 & 0.312 & 0.446 \\
\hline
\end{tabular}

Notes: Numbers represent ORs; $95 \% \mathrm{Cls}$ in square brackets. Reference category in round brackets. $* P<0.05 ; * * P<0.01 ; * * * P<0.001$.

Abbreviations: HAALSI, Health and Aging in Africa: A Longitudinal Study of an INDEPTH Community in South Africa; NCDs, non-communicable diseases; ADL, activities of daily living.

Table 3 Predictors of having no depression among elderly South Africans. HAALSI 2015

\begin{tabular}{|c|c|c|c|}
\hline & Overall & Male & Female \\
\hline $\begin{array}{l}\text { Age (60-69) } \\
70-79 \\
80+\end{array}$ & $\begin{array}{l}\text { I } \\
\text { I.054 } \\
{[0.826,1.345]} \\
0.781 \\
{[0.591,1.032]}\end{array}$ & $\begin{array}{l}\text { I } \\
\text { I.038 } \\
{[0.721,1.494]} \\
0.714 \\
{[0.463,1.102]}\end{array}$ & $\begin{array}{l}\mathrm{I} \\
\mathrm{I} .05 \mathrm{I} \\
{[0.754,1.466]} \\
0.805 \\
{[0.554, \mathrm{I} .169]}\end{array}$ \\
\hline $\begin{array}{l}\text { Sex (male) } \\
\text { Female }\end{array}$ & $\begin{array}{l}\mathrm{I} \\
0.690 * * \\
{[0.521,0.914]}\end{array}$ & NA & NA \\
\hline $\begin{array}{l}\text { Current marital status (unmarried) } \\
\text { Married }\end{array}$ & $\begin{array}{l}\mathrm{I} \\
\mathrm{I} .002 \\
{[0.784,1.280]}\end{array}$ & $\begin{array}{l}\text { I } \\
1.283 \\
{[0.904,1.820]}\end{array}$ & $\begin{array}{l}1 \\
0.819 \\
{[0.585,1.147]}\end{array}$ \\
\hline $\begin{array}{l}\text { Education (no formal education) } \\
\text { Some primary ( } 1-7 \text { years) } \\
\text { Some secondary (8-1I years) } \\
\text { Secondary or more ( } 12+\text { years) }\end{array}$ & $\begin{array}{l}I \\
0.866 \\
{[0.687,1.091]} \\
1.004 \\
{[0.598,1.686]} \\
0.598 \\
{[0.270,1.323]}\end{array}$ & $\begin{array}{l}\text { I } \\
0.919 \\
{[0.650,1.298]} \\
1.255 \\
{[0.637,2.470]} \\
0.714 \\
{[0.254,2.010]}\end{array}$ & $\begin{array}{l}I \\
0.855 \\
{[0.625,1.17 I]} \\
0.773 \\
{[0.338,1.767]} \\
0.437 \\
{[0.115,1.655]}\end{array}$ \\
\hline $\begin{array}{l}\text { Employed (yes) } \\
\text { No }\end{array}$ & $\begin{array}{l}\mathrm{I} \\
\mathrm{I} .122 \\
{[0.666,1.890]}\end{array}$ & $\begin{array}{l}\text { I } \\
\text { I.329 } \\
{[0.7|4,2.47|]}\end{array}$ & $\begin{array}{l}\text { I } \\
0.827 \\
{[0.302,2.265]}\end{array}$ \\
\hline $\begin{array}{l}\text { Wealth status (poor) } \\
\text { Not poor }\end{array}$ & $\begin{array}{l}\mathrm{I} \\
\mathrm{I} .165 \\
{[0.930,1.458]}\end{array}$ & $\begin{array}{l}\mathrm{I} \\
\mathrm{I} .133 \\
{[0.803,1.598]}\end{array}$ & $\begin{array}{l}\mathrm{I} \\
\mathrm{I} .192 \\
{[0.883,1.608]}\end{array}$ \\
\hline $\begin{array}{l}\text { Living environment (not satisfactory) } \\
\text { Satisfactory }\end{array}$ & $\begin{array}{l}\text { I } \\
\text { I.I } 33 \\
{[0.545,2.356]}\end{array}$ & $\begin{array}{l}\text { I } \\
0.599 \\
{[0.129,2.776]}\end{array}$ & $\begin{array}{l}\text { I } \\
\text { I.50| } \\
{[0.629,3.583]}\end{array}$ \\
\hline $\begin{array}{l}\text { Ever smoker (no) } \\
\text { Yes }\end{array}$ & $\begin{array}{l}\text { I } \\
0.896 \\
{[0.660,1.218]}\end{array}$ & $\begin{array}{l}\text { I } \\
0.886 \\
{[0.630,1.247]}\end{array}$ & $\begin{array}{l}I \\
0.903 \\
{[0.364,2.239]}\end{array}$ \\
\hline $\begin{array}{l}\text { Ever drinks alcohol (no) } \\
\text { Yes }\end{array}$ & $\begin{array}{l}\mathrm{I} \\
\mathrm{I} .582 * * * \\
{[1.255,1.995]}\end{array}$ & $\begin{array}{l}\mathrm{I} \\
\mathrm{I} .635^{*} \\
{[1.099,2.432]}\end{array}$ & $\begin{array}{l}\mathrm{I} \\
\mathrm{I} .546 * * \\
{[1.154,2.073]}\end{array}$ \\
\hline $\begin{array}{l}\text { Takes exercise (no) } \\
\text { Yes }\end{array}$ & $\begin{array}{l}\text { I } \\
\text { I.240 } \\
{[0.997,1.542]}\end{array}$ & $\begin{array}{l}\text { I } \\
0.982 \\
{[0.703,1.373]}\end{array}$ & $\begin{array}{l}\mathrm{I} \\
\mathrm{I} .478 * * \\
{[1.106,1.974]}\end{array}$ \\
\hline
\end{tabular}

(Continued) 
Table 3 (Continued).

\begin{tabular}{|c|c|c|c|}
\hline & Overall & Male & Female \\
\hline NCDs (none) & I & I & 1 \\
\hline \multirow[t]{2}{*}{ I } & $0.782 *$ & 0.702 & 0.831 \\
\hline & {$[0.619,0.987]$} & {$[0.491,1.005]$} & {$[0.608,1.136]$} \\
\hline \multirow[t]{2}{*}{$>1$} & $0.496 * * *$ & $0.391 * * *$ & $0.582 * *$ \\
\hline & {$[0.373,0.659]$} & {$[0.255,0.599]$} & {$[0.395,0.859]$} \\
\hline ADL difficulties (no) & I & I & 1 \\
\hline \multirow[t]{2}{*}{ Yes } & $0.464 * * *$ & $0.489 * *$ & $0.436 * * *$ \\
\hline & {$[0.348,0.618]$} & {$[0.3 \mid 2,0.768]$} & {$[0.299,0.637]$} \\
\hline $\mathrm{N}$ & 2627 & 1259 & 1368 \\
\hline adjusted $R^{2}$ & 0.292 & 0.338 & 0.319 \\
\hline
\end{tabular}

Notes: Numbers represent ORs; $95 \% \mathrm{Cls}$ in square brackets. Reference category in round brackets. $* P<0.05 ; * * P<0.01 ; * * * P<0.001$.

Abbreviations: HAALSI, Health and Aging in Africa: A Longitudinal Study of an INDEPTH Community in South Africa; NCDs, non-communicable diseases; ADL, activities of daily living.

Table 4 Predictors of good subjective quality of life among elderly South Africans. HAALSI 20 I5

\begin{tabular}{|c|c|c|c|}
\hline & Overall & Male & Female \\
\hline $\begin{array}{l}\text { Age (60-69) } \\
70-79 \\
80+\end{array}$ & $\begin{array}{l}1 \\
0.889 \\
{[0.731,1.081]} \\
0.727 * * \\
{[0.576,0.918]}\end{array}$ & $\begin{array}{l}I \\
1.129 \\
{[0.850,1.500]} \\
0.812 \\
{[0.569,1.157]}\end{array}$ & $\begin{array}{l}\mathrm{I} \\
0.709 * \\
{[0.539,0.933]} \\
0.633 * * \\
{[0.461,0.870]}\end{array}$ \\
\hline $\begin{array}{l}\text { Sex (male) } \\
\text { Female }\end{array}$ & $\begin{array}{l}\text { I } \\
0.972 \\
{[0.776,1.218]}\end{array}$ & NA & NA \\
\hline $\begin{array}{l}\text { Current marital status (unmarried) } \\
\text { Married }\end{array}$ & $\begin{array}{l}\mathrm{I} \\
\mathrm{I} .086 \\
{[0.890,1.325]}\end{array}$ & $\begin{array}{l}\text { I } \\
\text { I.279 } \\
{[0.970,1.687]}\end{array}$ & $\begin{array}{l}\mathrm{I} \\
0.884 \\
{[0.663, \mathrm{I} .179]}\end{array}$ \\
\hline $\begin{array}{l}\text { Education (no formal education) } \\
\text { Some primary ( } 1-7 \text { years) } \\
\text { Some secondary (8-1I years) } \\
\text { Secondary or more ( } 12+\text { years) }\end{array}$ & $\begin{array}{l}\mathrm{I} \\
\mathrm{I} .623 * * * \\
{[1.337,1.970]} \\
\mathrm{I} .558^{*} \\
{[1.025,2.367]} \\
6.893^{* *} \\
{[2.078,22.87]}\end{array}$ & $\begin{array}{l}\text { I } \\
\text { I.329* } \\
{[1.007,1.754]} \\
\text { I.258 } \\
{[0.756,2.094]} \\
3.526 * \\
{[1.034,12.03]}\end{array}$ & $\begin{array}{l}1 \\
1.985 * * * \\
{[1.507,2.613]} \\
2.135 \\
{[0.984,4.633]} \\
1 \\
{[1,1]}\end{array}$ \\
\hline $\begin{array}{l}\text { Employed (yes) } \\
\text { No }\end{array}$ & $\begin{array}{l}1 \\
{[1, I]} \\
0.791 \\
{[0.504,1.244]}\end{array}$ & $\begin{array}{l}I \\
{[I, I]} \\
0.595 \\
{[0.334,1.059]}\end{array}$ & $\begin{array}{l}\mathrm{I} \\
{[1, \mathrm{I}]} \\
1.332 \\
{[0.607,2.922]}\end{array}$ \\
\hline $\begin{array}{l}\text { Wealth status (poor) } \\
\text { Not poor }\end{array}$ & $\begin{array}{l}\text { I } \\
\text { I.264* } \\
{[1.052,1.519]}\end{array}$ & $\begin{array}{l}\text { I } \\
1.497 * * \\
{[1.138,1.969]}\end{array}$ & $\begin{array}{l}\mathrm{I} \\
\mathrm{I} .100 \\
{[0.855,1.417]}\end{array}$ \\
\hline $\begin{array}{l}\text { Living environment (not satisfactory) } \\
\text { Satisfactory }\end{array}$ & $\begin{array}{l}I \\
1.399 \\
{[0.741,2.640]}\end{array}$ & $\begin{array}{l}\text { I } \\
0.688 \\
{[0.226,2.088]}\end{array}$ & $\begin{array}{l}\text { I } \\
2.171 \\
{[0.955,4.935]}\end{array}$ \\
\hline
\end{tabular}


Table 4 (Continued).

\begin{tabular}{|c|c|c|c|}
\hline & Overall & Male & Female \\
\hline $\begin{array}{l}\text { Ever smoker (no) } \\
\text { Yes }\end{array}$ & $\begin{array}{l}\text { I } \\
0.794 \\
{[0.618,1.019]}\end{array}$ & $\begin{array}{l}\text { I } \\
0.738^{*} \\
{[0.560,0.972]}\end{array}$ & $\begin{array}{l}\mathrm{I} \\
\mathrm{I} .077 \\
{[0.484,2.397]}\end{array}$ \\
\hline $\begin{array}{l}\text { Ever drinks alcohol (no) } \\
\text { Yes }\end{array}$ & $\begin{array}{l}\mathrm{I} \\
\mathrm{I} .229 * \\
{[1.015,1.487]}\end{array}$ & $\begin{array}{l}\mathrm{I} \\
\mathrm{I} .286 \\
{[0.952,1.738]}\end{array}$ & $\begin{array}{l}\text { I } \\
\text { I.I } 57 \\
{[0.900,1.488]}\end{array}$ \\
\hline $\begin{array}{l}\text { Takes exercise (no) } \\
\text { Yes }\end{array}$ & $\begin{array}{l}\mathrm{I} \\
1.013 \\
{[0.843,1.217]}\end{array}$ & $\begin{array}{l}\text { I } \\
\text { I.III } \\
{[0.853,1.448]}\end{array}$ & $\begin{array}{l}\mathrm{I} \\
0.951 \\
{[0.735,1.229]}\end{array}$ \\
\hline $\begin{array}{l}\text { NCDs (none) } \\
\text { I } \\
>1\end{array}$ & $\begin{array}{l}\text { I } \\
1.030 \\
{[0.854,1.242]} \\
0.654 * * \\
{[0.511,0.836]}\end{array}$ & $\begin{array}{l}\text { I } \\
\text { I.043 } \\
{[0.789,1.379]} \\
0.561 * * \\
{[0.391,0.804]}\end{array}$ & $\begin{array}{l}1 \\
1.030 \\
{[0.797,1.332]} \\
0.724 \\
{[0.514,1.019]}\end{array}$ \\
\hline $\begin{array}{l}\text { ADL difficulties (no) } \\
\text { Yes }\end{array}$ & $\begin{array}{l}\text { I } \\
0.450 * * * \\
{[0.344,0.589]}\end{array}$ & $\begin{array}{l}\mathrm{I} \\
0.483 * * * \\
{[0.324,0.721]}\end{array}$ & $\begin{array}{l}\mathrm{I} \\
0.430 * * * \\
{[0.297,0.622]}\end{array}$ \\
\hline$N$ & 2627 & 1259 & 1357 \\
\hline adjusted $R^{2}$ & 0.540 & 0.421 & 0.496 \\
\hline
\end{tabular}

Notes: Numbers represent ORs; $95 \% \mathrm{Cls}$ in square brackets. Reference category in round brackets. $* P<0.05 ; * * P<0.01 ; * * * P<0.001$.

Abbreviations: HAALSI, Health and Aging in Africa: A Longitudinal Study of an INDEPTH Community in South Africa; NCDs, non-communicable diseases; ADL, activities of daily living.

chronic conditions was found to have an inverse association with subjective health in a Thai population as well. ${ }^{40}$ Health limiting conditions, especially functional difficulties can impact subjective health and well-being through many complex pathways, including poor appetite and nutritional status, reduced immunity, capacity to take exercise, social isolation and loneliness, and lack of access to care services. Our findings contribute to the existing evidence on the negative influences of chronic multimorbidity and ADL difficulties among elderly population, and support the need for enhanced efforts to address these health limiting conditions especially among rural populations due to less availability of quality health care resources.

As far as we are concerned, this is the first study to report the associations between chronic multimorbidity and ADL difficulties among an elderly population in a rural setting in Africa. This was a sub-national survey and data were not nationally representative. Nonetheless, our findings provide several important insights that can prove beneficial for health policy makers and future researchers. The findings should however be interpreted in light of several limitations. The outcome variables were self-reported and hence may not reflect the exact health and life circumstances. We also had no control over the selection of variables and were unable to include several important variables such as environmental, dietary, and cultural factors that are inextricably linked with health and well-being. To partially overcome this shortcoming, we used respondents' rating of living environment which is likely to capture an overall scenario of factors such as housing, safety, quality of air and water. We also had no data on the level of physical exercise, smoking, and drinking which are well-documented predictors of population health. Finally, the analysis was cross-sectional and hence the associations cannot be used to infer causality.

\section{Conclusion}

Based on the data from the HAALSI survey, the present study assessed the predictors of subjective health, depression, and QoL among elderly men and women in rural South Africa. Findings showed that more than $2 / 5$ and 2/3 of the participants reported good health and good QoL respectively, with about $1 / 5$ having reported depressive symptoms. Significant age and sex disparities were 
observed in the likelihood of reporting good SRH and QoL. We also found a positive association between several biopsychosocial factors such as current marital status, employment, satisfaction with living environment, tobacco use behavior, absence of chronic conditions and ADL difficulties. In light of these findings, it is recommended that geriatric health promotion programs should pay attention to the biopsychosocial factors in an effort to improve health and QoL status among elderly populations.

\section{Acknowledgments}

We wish to thank the Inter-university Consortium for Political and Social Research for making the data publicly available that have made this study possible. The National Natural Science Foundation of China (71503089) and the Fundamental Research Funds for the Central Universities (no: 2019WA01) supported this research.

\section{Disclosure}

The authors report no conflicts of interest in this work.

\section{References}

1. GBD 2015 Mortality and Causes of Death Collaborators.Global, regional, and national life expectancy, all-cause mortality, and cause-specific mortality for 249 causes of death, 1980-2015: a systematic analysis for the Global Burden of Disease Study 2015. Lancet. 2016;388 (10053):1459-1544.

2. WHO | life expectancy [Internet]. WHO. Available from: http://www. who.int/gho/mortality_burden_disease/life_tables/situation_trends_ text/en/. Accessed December 24, 2018.

3. de-Graft Aikins A, Unwin N, Agyemang C, Allotey P, Campbell C, Arhinful D. Tackling Africa's chronic disease burden: from the local to the global. Global Health. 2010;6:5. doi:10.1186/1744-8603-6-5

4. Stuckler D. Population causes and consequences of leading chronic diseases: a comparative analysis of prevailing explanations. Milbank Q. 2008;86(2):273-326. doi:10.1111/j.1468-0009.2008.00522.x

5. Baingana FK, Bos ER. Changing patterns of disease and mortality in SubSaharan Africa: an overview. In: Jamison DT, Feachem RG, Makgoba MW, et al. editors. Disease and Mortality in Sub-Saharan Africa. 2nd. Washington (DC): World Bank; 2006. Available from: http://www.ncbi. nlm.nih.gov/books/NBK2281/. Accessed December 24, 2018.

6. Ameh S, Klipstein-Grobusch K, D'ambruoso L, Kahn K, Tollman SM, Gómez-Olivé FX. Quality of integrated chronic disease care in rural South Africa: user and provider perspectives. Health Policy Plan. 2017;32(2):257-266.

7. Duffy M, Ojikutu B, Andrian S, Sohng E, Minior T, Hirschhorn LR. Non-communicable diseases and HIV care and treatment: models of integrated service delivery. Trop Med Int Health. 2017;22(8):926-937. doi:10.1111/tmi. 12987

8. Mahomed $\mathrm{OH}$, Asmall S. Development and implementation of an integrated chronic disease model in South Africa: lessons in the management of change through improving the quality of clinical practice. Int J Integr Care. 2015;15. doi:10.5334/ijic.1454

9. Mayosi BM, Lawn JE, van Niekerk A, et al. Health in South Africa: changes and challenges since 2009. Lancet. 2012;380(9858):20292043. doi:10.1016/S0140-6736(12)61814-5
10. Mayosi BM, Flisher AJ, Lalloo UG, Sitas F, Tollman SM, Bradshaw D. The burden of non-communicable diseases in South Africa. Lancet. 2009;374(9693):934-947. doi:10.1016/S0140-6736(09)61069-2

11. No suitable care for SA's elderly population [Internet]. Health-e; 2018 [cited 2018 December 24]. Available from: https://www.health-e.org. za/2018/08/22/no-suitable-care-for-sas-elderly-population/. Accessed July $1,2019$.

12. Gradidge PJ-L, Crowther NJ. Review: metabolic Syndrome in Black South African Women. EthnDis. 2017;27(2):189-200.

13. le R Booysen F. Urban-rural inequalities in health care delivery in South Africa. Dev South Afr. 2003;20(5):659-673. doi:10.1080/ 0376835032000149298

14. van der Hoeven M, Kruger A, Greeff M. Differences in health care seeking behaviour between rural and urban communities in South Africa. Int J Equity Health. 2012;11:31. doi:10.1186/1475-9276-11-31

15. McLaren ZM, Ardington C, Leibbrandt M. Distance decay and persistent health care disparities in South Africa. BMC Health Serv Res. 2014;14. doi:10.1186/s12913-014-0541-1

16. van Heerden A, Barnabas RV, Norris SA, Micklesfield LK, van Rooyen H, Celum C. High prevalence of HIV and non-communicable disease (NCD) risk factors in rural KwaZulu-Natal, South Africa. $J$ Int AIDS Soc. 2017;20(2):e25012. doi:10.1002/jia2.25012

17. He Z, Cheng Z, Bishwajit G, Zou D. Wealth inequality as a predictor of subjective health, happiness and life satisfaction among Nepalese women. Int $J$ Environ Res Public Health. 2018;15(12):2836. doi:10.3390/ijerph15061188

18. Health and Aging in Africa: A Longitudinal Study of an INDEPTH Community in South Africa (HAALSI) [Internet]. [cited 2018 Dec 29]. Available from: https://haalsi.org/about. Accessed July 1, 2019.

19. Manne-Goehler J, Siedner MJ, Montana L, et al. Hypertension and diabetes control along the HIV care cascade in rural South Africa. $J$ Int AIDS Soc. 2019;22(3):e25213. doi:10.1002/jia2.25213

20. Payne CF, Gómez-Olivé FX, Kahn K, Berkman L. Physical function in an aging population in rural South Africa: findings from HAALSI and cross-national comparisons with HRS sister studies. J Gerontol B Psychol Sci Soc Sci. 2017;72(4):665-679. doi:10.1093/geronb/ gbx030

21. Bishwajit G, O'Leary DP, Ghosh S, Yaya S, Shangfeng T, Feng Z. Physical inactivity and self-reported depression among middle- and older-aged population in South Asia: World health survey. $B M C$ Geriatr. 2017;17. doi:10.1186/s12877-017-0515-3

22. Hirve S. 'In general, how do you feel today?' - self-rated health in the context of aging in India. Glob Health Action. 2014;7. doi:10.3402/gha.v7.25484

23. Hays RD, Spritzer KL, Thompson WW, Cella D. U.S. general population estimate for "Excellent" to "Poor" Self-rated health item. $J$ Gen Intern Med. 2015;30(10):1511-1516. doi:10.1007/s11606-0153476-2

24. Geisner IM, Kirk JL, Mittmann AJ, Kilmer JR, Larimer ME. College students' perceptions of depressed mood: exploring accuracy and associations. Prof Psychol Res Pr. 2015;46(5):375-383. doi: $10.1037 /$ pro0000039

25. Kobau R, Safran MA, Zack MM, Moriarty DG, Chapman D. Sad, blue, or depressed days, health behaviors and health-related quality of life, behavioral risk factor surveillance system, 1995-2000. Health Qual Life Outcomes. 2004;2:40. doi:10.1186/1477-7525-2-40

26. Cheung F, Lucas RE. Assessing the validity of single-item life satisfaction measures: results from three large samples. Qual Life Res. 2014;23(10):2809-2818. doi:10.1007/s11136-014-0726-4

27. Wade DT, Halligan PW. The biopsychosocial model of illness: a model whose time has come. ClinRehabil. 2017;31(8):995-1004.

28. Kusnanto H, Agustian D, Hilmanto D. Biopsychosocial model of illnesses in primary care: A hermeneutic literature review. $J$ Family Med Prim Care. 2018;7(3):497-500. doi:10.4103/jfmpc. jfmpc_145_17 
29. Ghose B, AbdoulRazak MY. Memory and learning complaints in relation to depression among elderly people with multimorbidity. Geriatrics. 2017;2(2):15. doi:10.3390/geriatrics2020015

30. Kim HC, Oh SM. Noncommunicable diseases: current status of major modifiable risk factors in Korea. J Prev Med Public Health. 2013;46(4):165-172. doi:10.3961/jpmph.2013.46.4.165

31. Ghose B, Feng D, Tang S, et al. Women's decision-making autonomy and utilisation of maternal healthcare services: results from the Bangladesh Demographic and Health Survey. BMJ Open. 2017;7 (9):e017142. doi:10.1136/bmjopen-2017-017142

32. Son DT, Oh J, Heo J, et al. Early sexual initiation and multiple sexual partners among Vietnamese women: analysis from the multiple indicator cluster survey, 2011. Glob Health Action. 2016;9:29575. doi:10.3402/gha.v9.29575

33. Ghose B. Frequency of TV viewing and prevalence of overweight and obesity among adult women in Bangladesh: a cross-sectional study. BMJ Open. 2017;7(1):e014399. doi:10.1136/bmjopen-2016-014399

34. Fonta CL, Nonvignon J, Aikins M, Nwosu E, Aryeetey GC. Predictors of self-reported health among the elderly in Ghana: a cross sectional study. BMC Geriatr. 2017;17. doi:10.1186/s12877-017-0515-3
35. Cao Y, Krause JS, Saunders LL, Clark JMR. Impact of marital status on 20-year subjective well-being trajectories. Top Spinal Cord Inj Rehabil. 2015;21(3):208-217. doi:10.1310/sci21 03-208

36. Han K-T, Park E-C, Kim J-H, Kim SJ, Park S. Is marital status associated with quality of life? Health Qual Life Outcomes. 2014;12. doi:10.1186/s12955-014-0109-0

37. Hosseinpoor AR, Williams JS, Amin A, et al. Social determinants of self-reported health in women and men: understanding the role of gender in population health. PLoS One. 2012;7(4):e34799. doi:10.1371/journal.pone.0034799

38. Albert PR. Why is depression more prevalent in women? $J$ Psychiatry Neurosci. 2015;40(4):219-221. doi:10.1503/jpn

39. Abate KH. Gender disparity in prevalence of depression among patient population: a systematic review. Ethiop J Health Sci. 2013;23(3):283-288.

40. Haseen F, Adhikari R, Soonthorndhada K. Self-assessed health among Thai elderly. BMC Geriatr. 2010;10:30. doi:10.1186/14712318-10-30

\section{Publish your work in this journal}

Clinical Interventions in Aging is an international, peer-reviewed journal focusing on evidence-based reports on the value or lack thereof of treatments intended to prevent or delay the onset of maladaptive correlates of aging in human beings. This journal is indexed on PubMed Central, MedLine, CAS, Scopus and the Elsevier
Bibliographic databases. The manuscript management system is completely online and includes a very quick and fair peer-review system, which is all easy to use. Visit http://www.dovepress.com/ testimonials.php to read real quotes from published authors. 